\title{
Serum obestatin level strongly correlates with lipoprotein subfractions in non- diabetic obese patients
}

\author{
Anita Szentpéteri ${ }^{1}$, Hajnalka Lőrincz ${ }^{1}$, Sándor Somodi ${ }^{1}$, Viktória Evelin Varga ${ }^{1}$, György Paragh Jr², Ildikó Seres ${ }^{1}$, \\ György Paragh ${ }^{1}$ and Mariann Harangi ${ }^{*}$
}

\begin{abstract}
Background: Obestatin is a ghrelin-associated peptide, derived from preproghrelin. Although many of its effects are unclear, accumulating evidence supports positive actions on both metabolism and cardiovascular function. To date, level of obestatin and its correlations to the lipid subfractions in non-diabetic obese (NDO) patients have not been investigated.

Methods: Fifty NDO patients (BMl: $41.96 \pm 8.6 \mathrm{~kg} / \mathrm{m}^{2}$ ) and thirty-two normal-weight, age- and gender-matched healthy controls (BMI: $24.16 \pm 3.3 \mathrm{~kg} / \mathrm{m}^{2}$ ) were enrolled into our study. Obestatin level was measured by ELISA. Lowdensity lipoprotein (LDL) and high-density lipoprotein (HDL) subfractions, intermediate density lipoprotein (IDL) and very low-density lipoprotein (VLDL) levels and mean LDL size were detected by nongradient polyacrylamide gel electrophoresis (Lipoprint).

Results: Serum level of obestatin was significantly lower in NDO patients compared to controls (3.01 \pm 0.5 vs. 3.29 $\pm 0.6 \mu \mathrm{g} / \mathrm{ml}, p<0.05)$. We found significant negative correlations between the level of obestatin and BMI $(r=-0.33$; $p<0.001)$, level of serum glucose $(r=-0.27, p<0.05)$, HbA1c $(r=-0.38 ; p<0.001)$ and insulin $(r=-0.34 ; p<0.05)$. Significant positive correlation was found between obestatin level and the levels of ApoA1 $(r=0.25 ; p<0.05)$, large HDL subfraction ratio and level $(r=0.23 ; p<0.05$ and $r=0.24 ; p<0.05)$, IDL $(r=0.25 p<0.05)$ and mean LDL size $(r$ $=0.25 ; p<0.05)$. Serum VLDL ratio and level negatively correlated with obestatin $(r=-0.32 ; p<0.01$ and $r=-0.21$; $p=0.05)$. In multiple regression analysis obestatin was predicted only by VLDL level.
\end{abstract}

Conclusions: Based on our data, measurement of obestatin level in obesity may contribute to understand the interplay between gastrointestinal hormone secretion and metabolic alterations in obesity.

Keywords: Obestatin, Metabolic syndrome, Diabetes, Obesity, Hyperlipidemia

\section{Background}

Obesity is one of the leading causes of morbidity and mortality in the world. Globally, the prevalence of obesity has risen at an alarming rate over the past two decades [1]. Numerous studies have shown a clear relationship between obesity and risk of developing cardiovascular disease (CVD). A follow-up analysis from the Framingham study demonstrated high body mass index (BMI) as an independent risk factor for coronary artery disease (CAD),

\footnotetext{
* Correspondence: mharangi@hotmail.com

${ }^{1}$ Department of Internal Medicine, Faculty of Medicine, University of

Debrecen, Nagyerdei krt. 98, Debrecen H-4032, Hungary

Full list of author information is available at the end of the article
}

stroke, and overall CVD death [2]. Dyslipidemia is frequently associated to obesity and a well-known risk factor of CVD. The typical dyslipidemia associated with obesity consists of increased triglycerides (TG) and free fatty acid (FFA), decreased high-density lipoprotein-cholesterol (HDL-C) with HDL dysfunction and normal or slightly increased low-density lipoprotein-cholesterol (LDL-C) with increased small dense LDL. The concentration of plasma apolipoprotein (apo) B is also often increased [3, 4].

In the last few decades, it has been recognized that adipose tissue is a highly active metabolic and endocrine organ, and that secreted hormon-like proteins (adipokines) are important for metabolic homeostasis 
including lipid metabolism $[5,6]$. However, the regulatory effect of further proteins secreted by other tissues such as gastrointestinal tract has not been clarified.

Obestatin, a recently identified anorexigenic gut hormone, is a 23 amino acid peptide derived from the $\mathrm{C}$ terminal portion of the preproghrelin precursor [7]. There have been many contradicting reports regarding the role of obestatin in humans. Obestatin has opposite action to ghrelin on food intake and plays a role in energy balance [8]. Studies on the obestatin/ghrelin ratio in the gastrointestinal tract and plasma are associated with some diseases such as irritable bowel syndrome [9], obesity [10] and type 2 diabetes mellitus [11]. Plasma obestatin concentrations were negatively correlated with body mass index, insulin resistance index, and plasma leptin concentrations in obesity [12]. Fasting plasma concentration of obestatin, but not of ghrelin, was found to be reduced in insulin resistance and is positively associated with whole body insulin sensitivity in nondiabetic humans [13]. Therefore, obestatin may be a nutritional marker reflecting body adiposity and insulin resistance.

Although a previous study reported that it may also regulate lipid metabolism by inhibiting lipolysis [14], to date, the association of serum obestatin levels with the lipid subfractions has not been studied. Therefore, we aimed to measure the level of serum obestatin and evaluate its correlations to the lipid fractions and subfractions in non-diabetic obese (NDO) patients. We also investigated the possible associations between the concentration of obestatin and the HDL function characterized by HDLlinked anti- and pro-atherogenic enzymes: human paraoxonase-1 (PON1) and myeloperoxidase (MPO).

\section{Methods}

\section{Study population}

We enrolled fifty non-diabetic obese patients that were referred to our obesity outpatient clinic at Department of Internal Medicine, Faculty of Medicine, University of Debrecen, Hungary, and thirty-two healthy volunteers matched in sex and age. All participants provided written informed consent. The study protocol was approved by the Ethical Committee of University of Debrecen and the study was carried out in accordance with the Declaration of Helsinki. Obesity was defined as BMI $\geq 30 \mathrm{~kg} / \mathrm{m}^{2}$. Participants with active liver or endocrine disease (including any types of diabetes mellitus), cardiovascular disease, renal impairment or malignancy were excluded. Further exclusion criteria were pregnancy, lactation, current smoking, and alcoholism or drug dependence. Neither obese subjects nor lean healthy controls were taking lipid lowering, hyperglycemic, anti-inflammatory, antithrombotic medications or dietary supplements. None of participants were on antihypertensive treatment with exception of ten obese patients, who were on diuretics (indapamide) because of mild hypertension.

\section{Sample collection and laboratory measurements}

All venous blood samples were collected after 12-h of fasting. The routine laboratory parameters including fasting glucose, fructose amine, high sensitive $\mathrm{C}$-reactive protein (hsCRP), total-cholesterol, triglyceride, HDL-C, LDL-C, apoAI, apoB and lipoprotein(a) levels were determined from fresh sera with Cobas c501 analyzer (Roche Ltd., Mannheim, Germany) according to the manufacturer's instruction. To check non-diabetic status in study participants, we applied a routine $75 \mathrm{~g}$ oral glucose tolerance test (OGTT) after an overnight fast. At the same time, hemoglobin A1c (HbA1c) and fasting insulin were also performed according to the standard laboratory techniques. Homeostasis model assessment insulin resistance (HOMA-IR) was calculated with the formula of Matthews et al. [15]. Sera were kept frozen at $-70{ }^{\circ} \mathrm{C}$ for subsequent lipoprotein subfraction analysis and for enzyme-linked immunosorbent assay (ELISA) measurements.

\section{Lipoprotein subfraction analyses}

HDL subfractions were detected by an electrophoretic method on polyacrylamide gel with the Lipoprint System (Quantimetrix Corp., CA, USA) according to the manufacturer's instructions.Concisely, $25 \mu \mathrm{l}$ sera were added to the polyacrylamide gel tubes along with $300 \mu$ l loading gel solution. The tubes contained Sudan Black as a lipophilic dye and were photopolimerized at room temperature for $30 \mathrm{~min}$. Electrophoresis with tubes containing sera samples or the manufacturer's quality controls were performed at a constant of $3 \mathrm{~mA} /$ tube for $50 \mathrm{~min}$. Each electrophoresis chamber contained a quality control provided by the manufacturer (Liposure Serum Lipoprotein Control, Quantimetrix Corp., CA, USA). Subfraction bands were scanned with an ArtixScan M1 digital scanner (Microtek International Inc., CA, USA) and were identified by their mobility (Rf) using VLDL+LDL as the starting (Rf 0.0) and albumin as the ending ( $\mathrm{Rf} 1.0)$ reference point.

Ten HDL subfractions were differentiated between VLDL+LDL and albumin peaks, and were grouped into three major classes: large (from HDL1 to HDL3), intermediate (from HDL4 to HDL7) and small (HDL8 to HDL10) HDL subfractions. Cholesterol concentrations of the HDL particle subsets were calculated with Lipoware software (Quantimetrix Corp., CA, USA) by multiplying the total HDL-C concentration of the samples by the relative area under the curve (AUC) of the subfraction bands.

LDL subfractions were also determined using Lipoprint System (Quantimetrix Corp., CA, USA) according to the manufacturer's instructions. $25 \mu \mathrm{l}$ of serum samples were added to polyacrylamide gel tubes along with 
$200 \mu \mathrm{l}$ a loading gel solution containing Sudan Black as a lipophilic dye. The sample loading gel mixture was photopolymerized for $30 \mathrm{~min}$ at room temperature prior to electrophoresis at a constant of $3 \mathrm{~mA} /$ tube for $1 \mathrm{~h}$.

Lipoprotein fractions (bands) were identified after electrophoresis by their mobility (Rf) using VLDL as the reference point (Rf 0.0) and HDL as the ending reference point ( $R f$ 1.0). In between, up to seven LDL subfractions were distributed. The percentages of the area under the curve (AUC\%) for the VLDL, Midbands (C, B and A; comprising primarily IDL), LDL and HDL peaks, as well as mean LDL size $(\mathrm{nm})$ were calculated with Lipoware computer software (Quantimetrix Corp., CA, USA). Proportion of large LDL (large LDL \%) was defined as the sum of the percentage of LDL1 and LDL2, whereas proportion of small LDL (small-dense LDL \%) was defined as the sum of LDL3-LDL7. Cholesterol concentrations of LDL subfractions were determined by multiplying the relative AUC of subfractions by total cholesterol concentration of the sample. Calculated total LDL-C is comprised of the sum of the cholesterol in Midbands $\mathrm{C}$ through $\mathrm{A}$ and LDL subfractions (LDL1LDL7); and correlates strongly with the directly measured LDL-C [16].

\section{Determination of human paraoxonase-1 enzyme activities} PON1 paraoxonase activity was analyzed on a microtiter plate by a kinetic, semi-automated method using paraoxon (O,O-diethyl-O-p-nitrophenyl-phosphate, Sigma Aldrich) as a substrate. PON1 arylesterase activity was assayed with a phenylacetate substrate (Sigma Aldrich) and the hydrolysis of phenylacetate was monitored at $270 \mathrm{~nm}$ [17].

\section{ELISA measurements}

Plasma human obestatin was determined by EIA kit (Yanaihara Institute Inc., Shizuoka, Japan). Intra- and

Table 1 Anthropometric and routine laboratory parameters of study participants

\begin{tabular}{|c|c|c|c|}
\hline & Obese $(n=50)$ & Control $(n=32)$ & $P$ \\
\hline Gender (F/M) & $43 / 7$ & $27 / 5$ & ns \\
\hline Age (yrs) & $44.20 \pm 13.50$ & $41.78 \pm 5.97$ & ns \\
\hline Body mass index $\left(\mathrm{kg} / \mathrm{m}^{2}\right)$ & $41.96 \pm 8.63$ & $24.47 \pm 2.51$ & $<0.001$ \\
\hline Waist circumference (cm) & $119.76 \pm 16.87$ & $83.62 \pm 9.25$ & $<0.01$ \\
\hline hsCRP (mg/l) & $8.24(3.2-13.09)$ & $1.57(0.6-2.94)$ & $<0.001$ \\
\hline Fructose amine $(\mu \mathrm{mol} / \mathrm{l})$ & $225.32 \pm 27.95$ & $229.0 \pm 11.65$ & ns \\
\hline Thyroid stimulating hormone $(\mathrm{mU} / \mathrm{l})$ & $1.98 \pm 0.98$ & $1.93 \pm 1.15$ & ns \\
\hline \multicolumn{4}{|l|}{ Lipid parameters } \\
\hline Triglyceride (mmol/l) & $1.4(1.1-2.0)$ & $1.0(0.75-1.39)$ & $<0.01$ \\
\hline Total cholesterol (mmol/l) & $5.04 \pm 0.83$ & $5.07 \pm 0.78$ & ns \\
\hline HDL-cholesterol (mmol/l) & $1.36 \pm 0.33$ & $1.56 \pm 0.46$ & $<0.05$ \\
\hline LDL-cholesterol (mmol/l) & $3.17 \pm 0.74$ & $2.93 \pm 0.52$ & ns \\
\hline Apolipoprotein A-I (g/l) & $1.48 \pm 0.24$ & $1.68 \pm 0.31$ & $<0.01$ \\
\hline Apolipoprotein B (g/l) & $0.86 \pm 0.20$ & $0.94 \pm 0.18$ & ns \\
\hline Lipoprotein (a) (mg/l) & $248(120-586)$ & $70(30-214)$ & $<0.001$ \\
\hline \multicolumn{4}{|l|}{ Carbohydrate parameters } \\
\hline Hemoglobin A1c (\%) & $5.76 \pm 0.54$ & $5.07 \pm 0.33$ & $<0.001$ \\
\hline Fasting glucose (mmol/l) & $4.90 \pm 0.75$ & $4.82 \pm 0.48$ & ns \\
\hline OGTT $120 \mathrm{~min}$ & $7.00 \pm 2.01$ & & \\
\hline Fasting insulin (mU/l) & $21.01 \pm 15.91$ & & \\
\hline HOMA-IR & $3.75(2.4-6.52)$ & & \\
\hline \multicolumn{4}{|l|}{ Inflammatory and oxidative markers } \\
\hline Obestatin $(\mu \mathrm{g} / \mathrm{ml})$ & $3.01 \pm 0.5$ & $3.29 \pm 0.6$ & $<0.05$ \\
\hline Oxidized LDL (U/L) & $46.8 \pm 9.95$ & $41.1 \pm 9.57$ & $<0.01$ \\
\hline Paraoxonase activity (U/L) & $64.72(43.79-149.52)$ & $83.03(47.9-167.4)$ & ns \\
\hline Arylesterase activity (U/L) & $121.61 \pm 23.65$ & $131.1 \pm 28.75$ & ns \\
\hline Myeloperoxidase (ng/ml) & $280(148.3-386.3)$ & $207.9(125.8-265.2)$ & $<0.05$ \\
\hline
\end{tabular}

Values are presented as mean \pm standard deviation or median (lower quartile - upper quartile). Abbreviations: $H D L$ high-density lipoprotein, $h s C R P$ high sensitive C-reactive protein, LDL low-density-lipoprotein, OGT oral glucose tolerant test, HOMA-IR homeostasis model assessment insulin resistance, $n s$ non-significant 
inter-assay coefficients of variations (CV) were 3.5-9.9\% and 5.6-9.0\%, respectively. MPO and oxidized LDL (oxLDL) concentrations were determined by a commercially available ELISA kits (R\&D Systems, Minneapolis, MN, USA and Mercodia AB, Sweden, respectively) with 6.6-7.7 CV\% intra-, and 6.5-9.4 CV\% inter-assay (MPO) and 5.5-7.3 CV\% intra-, and 4-6.2 CV\% inter-assay precision (oxidized LDL). All assays were performed according to the recommendation of the manufacturer.

\section{Statistical methods}

Statistical analysis was performed by STATISTICA version 8.0 (Statsoft Inc., Tulsa, OK, USA). The normality of data distribution was tested by Kolmogorov-Smirnov test. Data were presented by descriptive analysis (means $\pm \mathrm{SD}$ in case of normal distribution, or medians [lower quartile - upper quartile] in the case of non-normal distribution). Comparisons between groups were performed by Student's unpaired t-test in case of normally distributed variables and by Mann-Whitney U-test in case of variables with non-normal distribution. Correlations between continuous variables were assessed by linear regression analysis using Pearson's test. Since the distribution of some variables of interest became normal upon base-10 logarithm transformation, we used the log values for correlation analyses. Multiple regression analysis was performed to determine which variables best predicted obestatin concentrations. Results were considered to be significant at the level of $p<0.05$.

\section{Results}

Anthropometric data and laboratory characteristics of study participants are summarized in Table 1 The NDO patients had extremely high BMI and slightly elevated hsCRP level compared to lean individuals. Although, there were several other differences in the laboratory parameters in NDO patients compared to lean controls, these data were found to be in the physiological range. Plasma triglyceride and lipoprotein(a) concentrations were found significantly higher, while the levels of HDL$\mathrm{C}$ and apoAI were significantly lower in the obese group compared to normal weight controls. HbA1C level was significantly higher in the obese individuals compared to the controls. Fasting glucose was in normal range in both groups and the blood glucose levels at $120 \mathrm{~min}$ of OGTT were not elevated in the obese group. On the basis of these laboratory parameters the obese patients involved into this study have neither diabetes nor impaired glucose tolerance.

Significantly higher VLDL, large LDL, small LDL and small HDL levels, while significantly lower IDL, mean LDL size, large HDL and intermediate HDL levels were found in NDO patients compared to the control population (Table 2).

Serum level of obestatin was significantly lower in NDO patients compared to controls ( $3.01 \pm 0.5$ vs. 3.29 $\pm 0.6 \mu \mathrm{g} / \mathrm{ml}, p<0.05$ ) (Table 1). We found significant negative correlations between obestatin levels and BMI $(r=-0.33 ; p<0.001)$, serum glucose levels $(r=-0.27, p$

Table 2 Concentration and ratio of lipoprotein subfractions in non-diabetic obese and lean participants

\begin{tabular}{|c|c|c|c|}
\hline & Obese $(n=50)$ & Control $(n=32)$ & $P$ \\
\hline VLDL subfraction $(\mathrm{mmol} / \mathrm{l})$ & $1.165 \pm 0.17$ & $0.868 \pm 0.17$ & $<0.001$ \\
\hline Midband (IDL) (mmol/l) & $1.207 \pm 0.31$ & $1.505 \pm 0.38$ & $<0.001$ \\
\hline VLDL subfraction (\%) & $23.3 \pm 2.5$ & $17.1 \pm 2.3$ & $<0.001$ \\
\hline Midband (IDL) (\%) & $23.7 \pm 3.6$ & $29.6 \pm 5$ & $<0.001$ \\
\hline \multicolumn{4}{|l|}{ LDL subfractions } \\
\hline Large LDL (mmol/l) & $1.267(1.06-1.603)$ & $1.047(0.827-1.344)$ & $<0.01$ \\
\hline Small-dense LDL (mmol/l) & $0.091(0.026-0.155)$ & $0.026(0-0.052)$ & $<0.001$ \\
\hline Mean LDL size (nm) & $26.98 \pm 0.31$ & $27.26 \pm 0.37$ & $<0.001$ \\
\hline Large LDL (\%) & $25.8 \pm 4.1$ & $21.1 \pm 5.8$ & $<0.001$ \\
\hline Small-dense LDL (\%) & $1.96 \pm 1.57$ & $1.05 \pm 2.26$ & $<0.05$ \\
\hline \multicolumn{4}{|l|}{ HDL subfractions } \\
\hline Large HDL (mmol/l) & $0.284(0.207-0.388)$ & $0.453(0.31-0.608)$ & $<0.001$ \\
\hline Intermediate $\mathrm{HDL}(\mathrm{mmol} / \mathrm{l})$ & $0.6594(0.595-0.828)$ & $0.749(0.659-0.853)$ & $<0.05$ \\
\hline Small HDL (mmol/l) & $0.336(0.284-0.388)$ & $0.284(0.246-0.336)$ & $<0.01$ \\
\hline Large HDL (\%) & $22.5 \pm 5.7$ & $29.8 \pm 9.0$ & $<0.001$ \\
\hline Intermediate HDL (\%) & $52.3 \pm 3.4$ & $50.8 \pm 4.7$ & ns \\
\hline Small HDL (\%) & $25.2 \pm 5.9$ & $19.3 \pm 5.3$ & $<0.001$ \\
\hline
\end{tabular}

Values are presented as mean \pm standard deviation or median (lower-upper quartiles)

Abbreviations: $H D L$ high-density lipoprotein, $h S C R P$ high sensitive C-reactive protein, IDL intermediate density lipoprotein, $L D L$ low-density-lipoprotein, OGTT oral glucose tolerant test, HOMA-IR homeostasis, VLDL very low-density lipoprotein 
$<0.05)$, HbA1c $(r=-0.38 ; p<0.001)$ and insulin $(r=-$ $0.34 ; p<0.05$; data not shown).

Significant positive correlation was found between obestatin level and the levels of ApoA1 $(r=0.25 ; p<$ $0.05)$, the ratio in \% of large HDL subfractions $(r=$ $0.23 ; p<0.05)$ and the level of large HDL subfractions $(0.24 ; p<0.05)$. Small HDL subfraction ratio in \% showed negative, but non-significant correlation with obestatin level $(-0.21 ; p=0.06)$, while small HDL level did not show any correlation with obestatin (Fig. 1.). We detected significant positive correlation between obestatin level and mean LDL size $(r=0.25$; $p<0.05)$. Significant negative correlations were found between obestatin and ratio of VLDL in $\%(r=-0.32$; $p<0.01)$ and VLDL level $(r=-0.21 ; p=0.05)$, while there were significant positive correlations between obestatin and ratio of IDL in \% $(r=0.25 ; p<0.05)$ and IDL level $(r=0.23 ; p<0.05)$ (Fig. 2).
Increased oxLDL and MPO levels were found in NDO patients compared to the control population. PON1 paraoxonase and arylesterase acivities did not differ significantly between patients and controls (Table 1). We could not find significant correlations between obestatin and the levels of MPO and PON1 paraoxonase and arylesterase activities.

In multiple regression analysis obestatin was predicted only by VLDL level (Table 3 ).

\section{Discussion}

Obestatin acts as an anorectic hormone that decreases food intake, slows gastrointestinal motility and therefore reduces weight gain [12]. Previous studies in humans showed significantly lower plasma obestatin levels in diabetic or non-diabetic obese subjects compared to lean controls but failed to assess diabetes mellitus or impaired glucose tolerance status [18]. We found similar results in our obese subjects without diabetes.
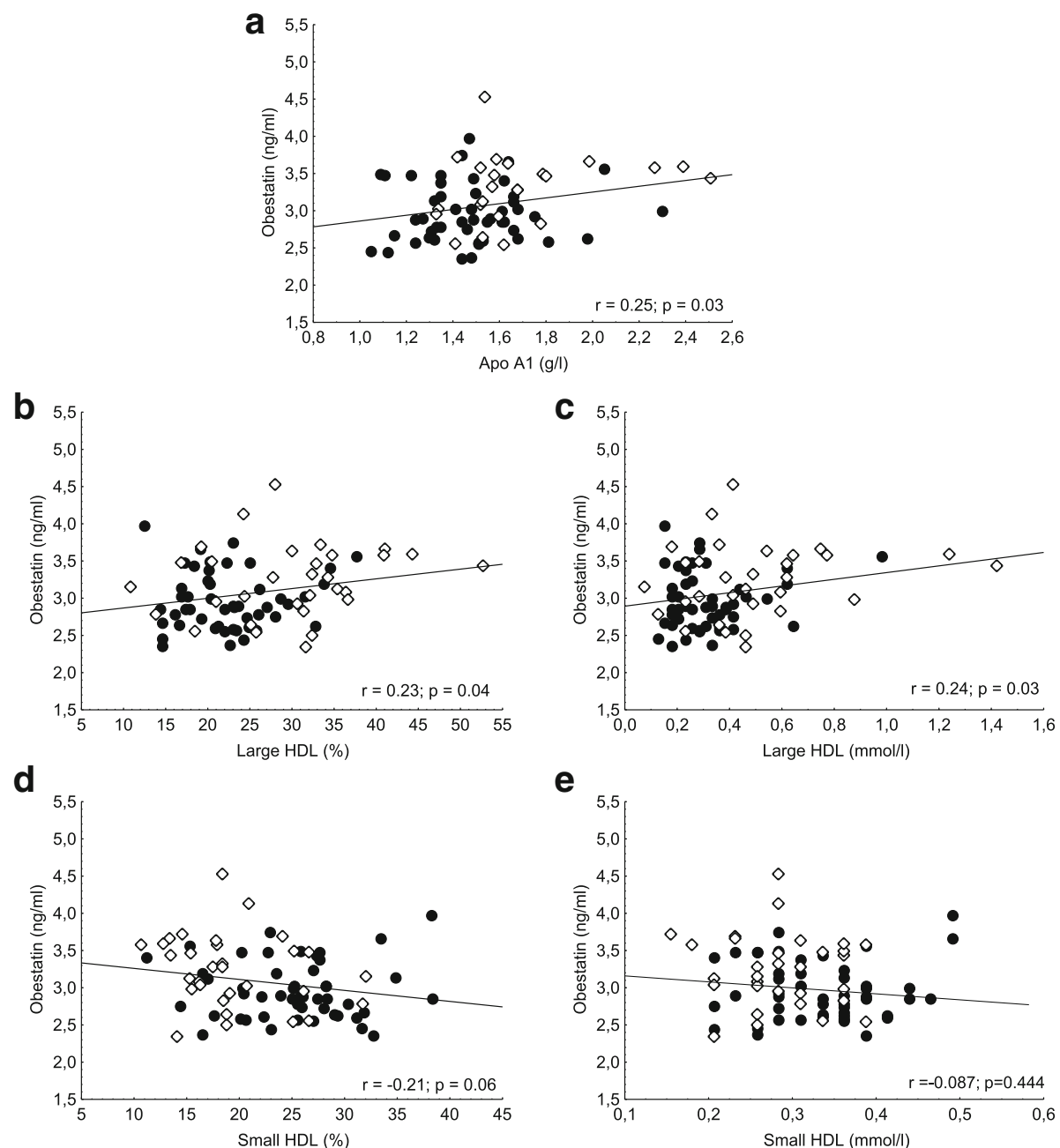

Fig. 1 Correlations between serum obestatin level and (a) apolipoprotein A1 (ApoA1); b large high-density lipoprotein subfraction ratio (large HDL \%); c large HDL subfraction level (large HDL); d small HDL subfraction ratio (small HDL \%); and (e) small HDL subfraction level (small HDL) in non-diabetic obese $(\bullet)$ and normal weight controls $(\boldsymbol{\nabla})$ 


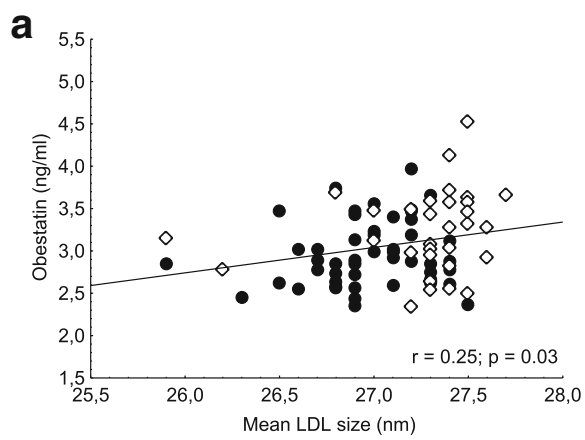

b

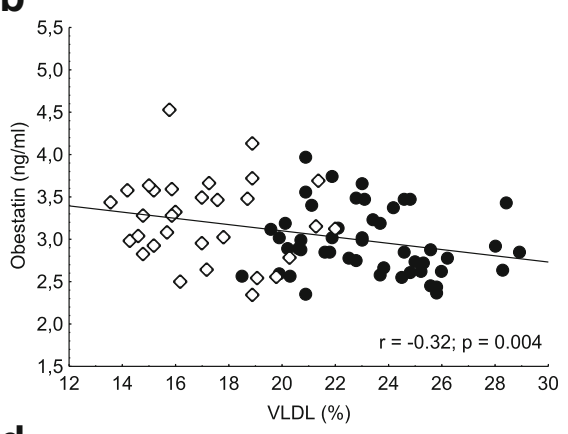

d

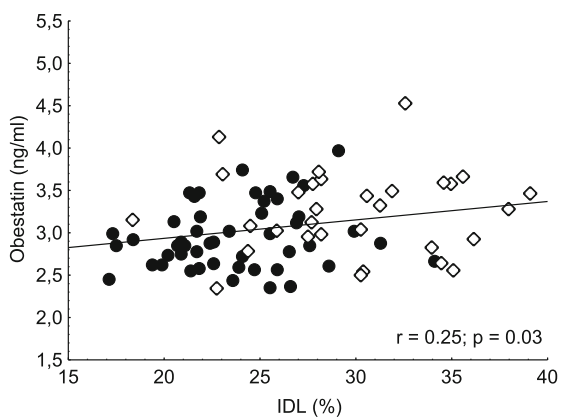

C

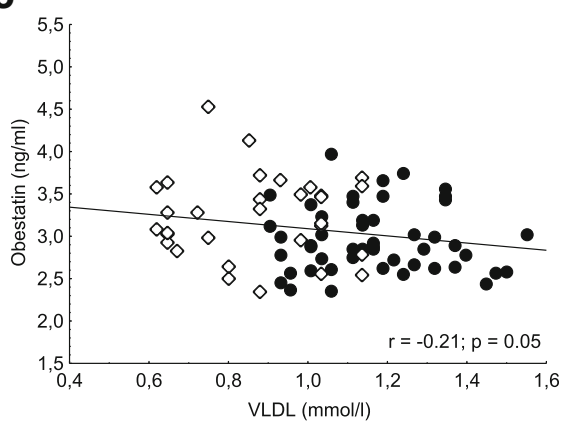

e

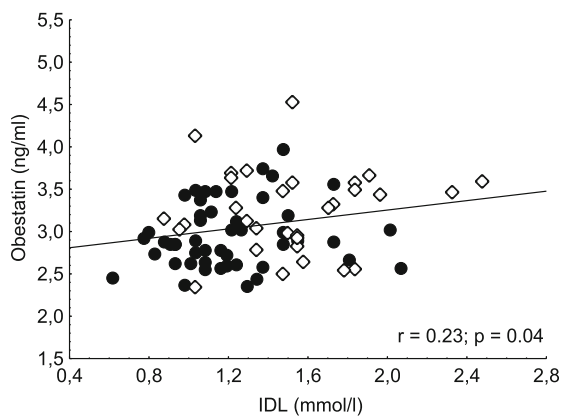

Fig. 2 Correlations between serum obestatin level and (a) mean low-density lipoprotein size (mean LDL size); b very low-density lipoprotein ratio (VLDL \%); c VLDL level (VLDL); $\mathbf{d}$ intermediate-density lipoprotein subfraction level (IDL\%) and (e) IDL level (IDL) in non-diabetic obese $(\bullet)$ and normal weight controls $(\nabla)$

Table 3 Multivariate analysis for obestatin as a dependent variable on all study participants

\begin{tabular}{lll}
\hline Variable & Beta & $p$-value \\
\hline Body mass index $\left(\mathrm{kg} / \mathrm{m}^{2}\right)$ & 0.073 & 0.09 \\
Glucose $(\mathrm{mmol} / \mathrm{l})$ & -0.22 & 0.80 \\
Hemoglobin A1c $(\%)$ & -0.05 & 0.22 \\
Apolipoprotein A1 $(\mathrm{g} / \mathrm{l})$ & -0.28 & 0.054 \\
VLDL $(\mathrm{mmol} / \mathrm{l})$ & -0.29 & $<0.05$ \\
IDL $(\mathrm{mmol} / \mathrm{l})$ & -0.03 & 0.36 \\
large HDL $(\mathrm{mmol} / \mathrm{l})$ & 0.413 & 0.06 \\
small HDL $(\mathrm{mmol} / \mathrm{l})$ & 0.069 & 0.69 \\
Mean LDL size $(\mathrm{nm})$ & -0.07 & 0.73
\end{tabular}

Abbreviations: $H D L$ high-density lipoprotein, IDL intermediate density lipoprotein, $L D L$ low-density-lipoprotein, OGTT oral glucose tolerant test, HOMA-IR homeostasis
The exact role of obestatin in regulation of lipoprotein levels is not completely clarified.

Some previous studies showed that it may regulate lipid metabolism by inhibiting lipolysis in 3 T3 and human subcutaneous and omental adipocytes isolated from lean and obese individuals and mice on high-fat diet $[19,20]$. Obestatin increases AMP kinase phosphorylation leading to enhanced lipolysis in adipocytes [20]. Moreover, administration of N-terminally PEGylated obestatin significantly reduced plasma triglyceride levels in rat [21]. Interestingly obestatin infusion reduced the key lipid transporter ATP-binding cassette A1 expression in cow white adipose tissue [22].

Correlations between obestatin levels and lipoprotein subfraction parameters have to the best of our knowledge have not previously been investigated. We found a 
significant positive correlation between obestatin level and the levels of ApoA1 and large HDL subfractions, which may indicate a possible connection between the abnormal gastrointestinal response and decreased hepatic ApoA1 expression in obesity. Furthermore, serum VLDL ratio and level negatively correlated with obestatin, which may be explained by the previously described association between the serum level of obestatin and carbohydrate metabolism, since insulin resistance and the higher level of serum glucose result in increased hepatic free fatty acid production leading to elevated VLDL level [23]. Moreover, in multiple regression analysis VLDL level was the only independent predictor of obestatin level. The negative VLDL correlation likely also explains the large HDL subfraction positive correlation to obestatin levels, which was approaching significance $(p=0.06)$ on multiple regression analysis. Increased transport of triglyceride from VLDL to HDL and cholesterol-esther from HDL to VLDL by cholesterolesther transfer protein lead to the formation of smaller and denser HDL particles with enhanced degradation and lower half lifespan, which results in low total HDL$\mathrm{C}$ levels and a shift towards smaller HDL subfractions [24].

We also investigated the activity of human paraoxonase-1, an antioxidant enzyme mainly associated with smaller HDL particles containing apolipoprotein J (clusterin) $[25,26]$. Although both paraoxonase and arylesterase activities of the enzyme tended to be lower in obese subjects, there were no significant differences in enzyme activities between the two study groups, despite the shift towards the smaller HDL subfractions. Furthermore, we found no significant correlation between obestatin levels and PON1 enzyme activity.

The level of another HDL associated, proatherogenic enzyme: myeloperoxidase was also investigated. In line with some previous studies $[27,28]$ we found significantly higher myeloperoxidase level in obese subjects compared to lean controls. Previous data shows that MPO, PON1, and HDL may bind to each other, forming a ternary complex, wherein PON1 partially inhibits MPO activity and MPO inactivates PON1 influencing endogenous oxidative stress and lipid peroxidation during inflammation [29]. In our previous study PON1 arylesterase activity was found to be an independent predictor of MPO levels in overweight hyperlipidemic, lipid-lowering therapynaive patients [30]. In the nondiabetic obese group there were no significant correlations either between paraoxonase activity and myeloperoxidase level or between obestatin and myeloperoxidase level.

A previous study showed obestatin increased oxLDL binding to macrophages [31]. Although, oxLDL level was significantly higher in obese patients, we could not find significant correlation between the levels of oxLDL and obestatin.

Some limitations of the study can be noted. The power of the study may be reduced because of the relatively small number of obese subjects. Obestatin secretion was found to be pulsatile and displayed an ultradian rhythmicity in a previous study [8]. We investigated fasting serum obestatin levels; however, postprandial levels of obestatin may show altered correlations with quantitative and qualitative parameters of lipoproteins.

\section{Conclusion}

We concluded that decreased level of obestatin may contribute to the development of metabolic syndrome and altered lipoprotein metabolism in obese patients even without disturbed insulin sensitivity. However, obestatin level does not correlate to HDL function markers including PON1 and MPO and has no effect on the level of oxidized LDL. Based on our data, measurement of obestatin level in obesity may contribute to understand the interplay between gastrointestinal hormone secretion and metabolic alterations in obesity.

\section{Abbreviations \\ BMI: Body mass index; CAD: Coronary artery disease; CVD: Cardiovascular disease; ELISA: Enzyme-linked immunosorbent assay; FFA: Free fatty acid; HbA1c: Hemoglobin A1c; HDL: High-density lipoprotein; HDL-C: High-density lipoprotein-cholesterol; HOMA-IR: Homeostasis model assessment - insulin resistance; hsCRP: High sensitive C-reactive protein; IDL: Intermediate density lipoprotein; LDL: Low-density lipoprotein; LDL-C: low-density lipoprotein- cholesterol; MPO: Myeloperoxidase; NDO: Non-diabetic obese; OGTT: Oral glucose tolerance test; oxLDL: Oxidized LDL; PON1: Human paraoxonase-1; TG: Triglycerides; VLDL: Very low-density lipoprotein}

\section{Acknowledgments}

Not applicable.

\section{Authors' contribution}

ASZ,VEV, HL: designed and performed experiments, analyzed data and revised manuscript; SS: collected samples; IS, MH: designed study, collected and analyzed data, wrote manuscript; GP Jr.: wrote and critically revised manuscript; GP, JB: critically revised manuscript. All authors read and approved the final manuscript.

\section{Funding}

This research was supported by a grant from the National Research, Development and Innovation (NFKI) (OTKA 115723) and by the GINOP-2.3.215-2016-00005 project. The project is co-financed by the European Union under the European Regional Development Fund.

\section{Availability of data and materials}

All data generated or analyzed during this study are included in this published article. All data generated or analyzed during the current study are available from the corresponding author on reasonable request.

\section{Ethics approval and consent to participate}

The work is conform to the guiding principles of the Declaration of Helsinki, and our study subjects gave informed consent of a study that has been approved by the Institutional Committee on Human Research at our institution. 


\section{Competing interests}

The authors declare that they have no competing interests.

\section{Publisher's Note}

Springer Nature remains neutral with regard to jurisdictional claims in published maps and institutional affiliations.

\section{Author details}

${ }^{1}$ Department of Internal Medicine, Faculty of Medicine, University of Debrecen, Nagyerdei krt. 98, Debrecen H-4032, Hungary. ²Department of Cell Stress Biology, Department of Dermatology, Roswell Park Cancer Institute, Buffalo, NY, USA

\section{Received: 10 October 2017 Accepted: 28 February 2018} Published online: 05 March 2018

\section{References}

1. Ng M, Fleming T, Robinson M, Thomson B, Graetz N, Margono C, Mullany EC, Biryukov S, Abbafati C, Abera SF, Abraham JP, Abu-Rmeileh NM, Achok T, FS AB, Alemu ZA, Alfonso R, Ali MK, Ali R, Guzman NA, Ammar W, Anwari P, Banerjee A, Barquera S, Basu S, Bennett DA, Bhutta Z, Blore J, Cabral N, Nonato IC, Chang JC, Chowdhury R, Courville KJ, Criqui MH, Cundiff DK, Dabhadkar KC, Dandona L, Davis A, Dayama A, Dharmaratne SD, Ding EL, Durrani AM, Esteghamati A, Farzadfar F, Fay DF, Feigin VL, Flaxman A, Forouzanfar MH, Goto A, Green MA, Gupta R, Hafezi-Nejad N, Hankey GJ, Harewood HC, Havmoeller R, Hay S, Hernandez L, Husseini A, Idrisov BT, Ikeda N, Islami F, Jahangir $E$, Jassal SK, Jee SH, Jeffreys M, Jonas JB, Kabagambe EK, Khalifa SE, Kengne AP, Khader YS, Khang YH, Kim D, Kimokoti RW, Kinge JM, Kokubo Y, Kosen S, Kwan G, Lai T, Leinsalu M, Li Y, Liang X, Liu S, Logroscino G, Lotufo PA, Lu Y, Ma J, Mainoo NK, Mensah GA, Merriman TR, Mokdad AH, Moschandreas J, Naghavi M, Naheed A, Nand D, Narayan KM, Nelson EL, Neuhouser ML, Nisar MI, Ohkubo T, Oti SO, Pedroza A, Prabhakaran D, Roy N, Sampson U, Seo H, Sepanlou SG, Shibuya K, Shiri R, Shiue I, Singh GM, Singh JA, Skirbekk V, Stapelberg NJ, Sturua L, Sykes BL, Tobias M, Tran BX, Trasande L, Toyoshima H, van de Vijver S, Vasankari TJ, Veerman JL, Velasquez-Melendez G, Vlassov W, Vollset SE, Vos T, Wang C, Wang $X$, Weiderpass E, Werdecker A, Wright JL, Yang YC, Yatsuya H, Yoon J, Yoon SJ, Zhao Y, Zhou M, Zhu S, Lopez AD, Murray CJ, Gakidou E. Global, regional, and national prevalence of overweight and obesity in children and adults during 1980-2013: a systematic analysis for the global burden of disease study 2013. Lancet. 2014;384:766-81.

2. Hubert HB, Feinleib M, McNamara PM, Castelli WP. Obesity as an independent risk factor for cardiovascular disease: a 26-year follow-up of participants in the Framingham heart study. Circulation. 1983;67:968-77.

3. Franssen R, Monajemi H, Stroes ES, Kastelein JJ. Obesity and dyslipidemia. Med Clin North Am. 2011;95:893-902.

4. Wang $H$, Peng DQ. New insights into the mechanism of low high-density lipoprotein cholesterol in obesity. Lipids Health Dis. 2011;10:176.

5. Luo L, Liu M. Adipose tissue in control of metabolism. J Endocrinol. 2016; 231:R77-99.

6. Lőrincz H, Katkó M, Harangi M, Somodi S, Gaál K, Fülöp P, Paragh G, Seres I. Strong correlations between circulating chemerin levels and lipoprotein subfractions in nondiabetic obese and nonobese subjects. Clin Endocrinol. 2014;81:370-7

7. Zhang JV, Ren PG, Avsian-Kretchmer O, Luo CW, Rauch R, Klein C, Hsueh AJ Obestatin, a peptide encoded by the ghrelin gene, opposes ghrelin's effects on food intake. Science. 2005;310:996-9.

8. Zizzari P, Longchamps R, Epelbaum J, Bluet-Pajot MT. Obestatin partially affects ghrelin stimulation of food intake and growth hormone secretion in rodents. Endocrinology. 2007;148:1648-53.

9. Sjölund K, Ekman R, Wierup N. Covariation of plasma ghrelin and motilin in irritable bowel syndrome. Peptides. 2010;31:1109-12.

10. Zhang N, Yuan C, Li Z, Li J, Li X, Li C, Li R, Wang SR. Meta-analysis of the relationship between obestatin and ghrelin levels and the ghrelin/obestatin ratio with respect to obesity. Am J Med Sci. 2011;341:48-55.

11. Qi X, Li L, Yang G, Liu J, Li K, Tang Y, Liou H, Boden G. Circulating obestatin levels in normal subjects and in patients with impaired glucose regulation and type 2 diabetes mellitus. Clin Endocrinol. 2007:66:593-7.

12. Nakahara T, Harada T, Yasuhara D, Shimada N, Amitani H, Sakoguchi T, Kamiji MM, Asakawa A, Inui A. Plasma obestatin concentrations are negatively correlated with body mass index, insulin resistance index, and plasma leptin concentrations in obesity and anorexia nervosa. Biol Psychiatry. 2008;64:252-5.

13. Anderwald-Stadler M, Krebs M, Promintzer M, Mandl M, Bischof MG, Nowotny P, Kästenbauer T, Luger A, Prager R, Anderwald C. Plasma obestatin is lower at fasting and not suppressed by insulin in insulinresistant humans. Am J Physiol Endocrinol Metab. 2007;293:E1393-8.

14. Wojciechowicz T, Skrzypski M, Kołodziejski PA, Szczepankiewicz D, Pruszyńska-Oszmałek E, Kaczmarek P, Strowski MZ, Nowak KW. Obestatin stimulates differentiation and regulates lipolysis and leptin secretion in rat preadipocytes. Mol Med Rep. 2015;12:8169-75

15. Matthews DR, Hosker JP, Rudenski AS, Naylor BA, Treacher DF, Turner RC. Homeostasis model assessment: insulin resistance and beta-cell function from fasting plasma glucose and insulin concentrations in man. Diabetologia. 1985;28:412-9.

16. Hoefner DM, Hodel SD, O'Brien JF, Branum EL, Sun D, Meissner I, McConnell JP. Development of a rapid, quantitative method for $L D L$ subfractionation with use of the Quantimetrix Lipoprint LDL system. Clin Chem. 2001;47:266-74.

17. Fülöp P, Seres I, Lőrincz H, Harangi M, Somodi S, Paragh G. Association of chemerin with oxidative stress, inflammation and classical adipokines in non-diabetic obese patients. J Cell Mol Med. 2014;18:1313-20.

18. Huda MS, Durham BH, Wong SP, Deepak D, Kerrigan D, McCulloch P, Ranganath L, Pinkney J, Wilding JP. Plasma obestatin levels are lower in obese and post-gastrectomy subjects, but do not change in response to a meal. Int J Obes. 2008:32:129-35.

19. Miegueu P, St Pierre D, Broglio F, Cianflone K. Effect of desacyl ghrelin, obestatin and related peptides on triglyceride storage, metabolism and GHSR signaling in 3T3-L1 adipocytes. J Cell Biochem. 2011;112:704-14.

20. Granata R, Gallo D, Luque RM, Baragli A, Scarlatti F, Grande C, Gesmundo I, Córdoba-Chacón J, Bergandi L, Settanni F, Togliatto G, Volante M, Garetto S, Annunziata M, Chanclón B, Gargantini E, Rocchietto S, Matera L, Datta G, Morino M, Brizzi MF, Ong H, Camussi G, Castaño JP, Papotti M, Ghigo E. Obestatin regulates adipocyte function and protects against diet-induced insulin resistance and inflammation. FASEB J. 2012;26:3393-411.

21. Agnew A, Calderwood D, Chevallier OP, Greer B, Grieve DJ, Green BD. Chronic treatment with a stable obestatin analog significantly alters plasma triglyceride levels but fails to influence food intake; fluid intake; body weight; or body composition in rats. Peptides. 2011:32:755-62.

22. Grala TM, Kay JK, Walker CG, Sheahan AJ, Littlejohn MD, Lucy MC, Roche JR. Expression analysis of key somatotropic axis and liporegulatory genes in ghrelinand obestatin-infused dairy cows. Domest Anim Endocrinol. 2010;39:76-83.

23. Mishra AK, Dubey V, Ghosh AR. Obesity: an overview of possible role(s) of gut hormones, lipid sensing and gut microbiota. Metabolism. 2016;65:48-65.

24. Kardassis D, Mosialou I, Kanaki M, Tiniakou I, Thymiakou E. Metabolism of HDL and its regulation. Curr Med Chem. 2014;21:2864-80.

25. Bergmeier $C$, Siekmeier $R$, Gross W. Distribution spectrum of paraoxonase activity in HDL fractions. Clin Chem. 2004:50:2309-15.

26. Kelso GJ, Stuart WD, Richter RJ, Furlong CE, Jordan-Starck TC, Harmony JA. Apolipoprotein $\mathrm{J}$ is associated with paraoxonase in human plasma. Biochemistry. 1994;33:832-9.

27. Zur B, Look M, Holdenrieder S, Stoffel-Wagner B. Elevated plasma myeloperoxidase concentration in adults with obesity. Clin Chim Acta. 2011;412:1891-2

28. Borato DC, Parabocz GC, Ribas JT, Netto HP, Erdmann FC, Wiecheteck LD, Manente FA, Mello LR, Belló C, dos Santos FA, Borba LM, Vellosa JC. Biomarkers in obesity: serum myeloperoxidase and traditional cardiac risk parameters. Exp Clin Endocrinol Diabetes. 2016;124:49-54.

29. Huang Y, Wu Z, Riwanto M, Gao S, Levison BS, Gu X, Fu X, Wagner MA, Besler C, Gerstenecker G, Zhang R, Li XM, DiDonato AJ, Gogonea V, Tang WH, Smith JD, Plow EF, Fox PL, Shih DM, Lusis AJ, Fisher EA, DiDonato JA, Landmesser U. Hazen SL. Myeloperoxidase, paraoxonase-1, and HDL form a functional ternary complex. J Clin Invest. 2013;123:3815-28.

30. Zsíros N, Koncsos P, Lőrincz H, Seres I, Katkó M, Szentpéteri A, Varga VE, Fülöp P, Paragh G, Harangi M. Paraoxonase-1 arylesterase activity is an independent predictor of myeloperoxidase levels in overweight patients with or without cardiovascular complications. Clin Biochem. 2016:49:862-7.

31. Kellokoski E, Kunnari A, Jokela M, Mäkelä S, Kesäniemi YA, Hörkkö S. Ghrelin and obestatin modulate early atherogenic processes on cells: enhancement of monocyte adhesion and oxidized low-density lipoprotein binding. Metabolism. 2009:58:1572-80. 